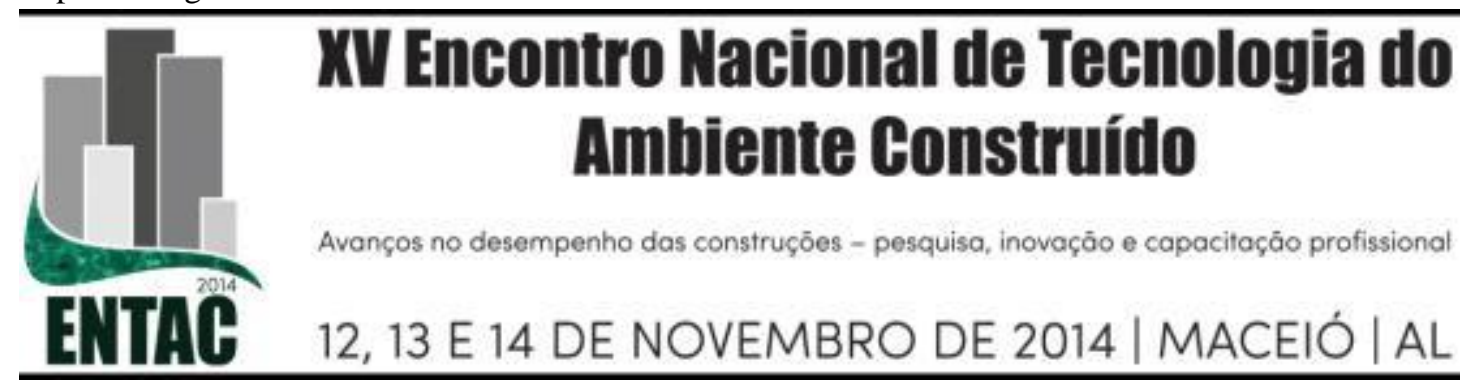

\title{
ANÁLISE DO DESEMPENHO DA ILUMINAÇÃO NATURAL DE SALAS DE AULA DE DESENHO EM VITÓRIA (ES)
}

\author{
VENTORIM, F. C. (1); BRAGATTO, L. R. (2); RODRIGUES, M. L. de B. (3); \\ DIAS, I. P. (4); MARQUES, A. C. R. (5); DINIZ, A. C. (6); ACHIAMÉ, G. G. (7); \\ SAUER, A. S. (8); REMBISKI, F. D. (9).
}

(1) Faculdade Brasileira, feventorim@gmail.com; (2) Faculdade Brasileira, larissabragatto@hotmail.com;

(3) Faculdade Brasileira, marialuiza@email.com; (4) Faculdade Brasileira, ingridpizetta@gmail.com; (5)

Faculdade Brasileira, anna28caroll@hotmail.com; (6) Faculdade Brasileira, anadiniz17@gmail.com; (7)

Faculdade Brasileira, giachiame@hotmail.com; (8) Faculdade Brasileira, alinesisa@ hotmail.com; (9)

Faculdade Brasileira, frembiski@gmail.com

\begin{abstract}
RESUMO
As crises energéticas ocorridas em vários países, inclusive no Brasil, alavancaram a necessidade de rever o consumo energético. As edificações são responsáveis por grande parte do consumo de energia elétrica. No Brasil, cerca de $20 \%$ deste consumo é destinado à iluminação de ambientes. O aproveitamento da luz natural favorece tanto a redução do consumo de energia como a melhoria das condições de conforto. Em um ambiente escolar, a qualidade do aprendizado é função direta do grau de conforto ambiental apresentado pelo espaço. Nesse caso, a iluminância adequada aliada a uma distribuição uniforme da luz são essenciais para o desempenho dos alunos. Diante disso, este trabalho objetiva analisar o desempenho da iluminação natural de quatro salas de desenho localizadas em Vitória (ES), a fim de verificar as condições de conforto a que os usuários estão submetidos. Esta análise foi realizada através da comparação dos resultados das medições in loco de iluminância, seguindo a NBR 15215-4, e das percepções coletadas dos alunos, através de um questionário baseado em trabalhos já realizados por outros pesquisadores. Os resultados indicam que o sistema de iluminação natural das salas é insuficiente para promover o conforto lumínico dos usuários, tendo em vista que os níveis de iluminância medidos não atingem os níveis determinados pela NBR 8995-1. Ao comparar estes níveis com as percepções coletadas dos alunos esta hipótese foi confirmada. Sendo assim, para promover o nível de iluminância correto e, consequentemente, o conforto lumínico dos usuários é necessária a utilização do sistema de iluminação artificial. Entretanto, nota-se que as áreas mais próximas das janelas possuem iluminância próxima a adequada, e de acordo com as percepções dos alunos, os níveis de iluminação natural destas áreas são suficientes. Dessa forma, buscando redução no consumo energético, sugere-se a readequação do sistema de acionamento das fileiras de luminárias próximas as janelas.
\end{abstract}

Palavras-chave: Iluminação natural, conforto visual, percepção, eficiência energética, salas de aula.

\begin{abstract}
The energy crises in several countries, including Brazil, boosted the need to revise the energy consumption. The buildings are responsible for much of the electricity consumption. In Brazil, about $20 \%$ of this consumption is for the lighting environments. The use of natural light favors both reducing energy consumption and improving comfort conditions. In a school environment, the quality of learning is a direct function of the degree of environmental comfort presented by space. In this case, appropriate illuminance combined with a uniform distribution of light are essential to student achievement. Thus, this paper aims to analyze the performance of daylighting four drawing rooms located in Vitória (ES) in order to verify the conditions of comfort that users are subjected. This analysis was performed by comparing the results of in situ measurements of illuminance, following the NBR 15215-4, and the perceptions of students collected through a questionnaire based on previous work by other researchers. The results indicate that the system of natural lighting of the rooms is insufficient to promote luminal
\end{abstract}


comfort of users, considering that the measured illuminance levels do not reach the levels determined by the NBR 8995-1. By comparing these levels with the perceptions of students collected this hypothesis was confirmed. Therefore, to promote the proper level of illuminance and hence the use of artificial lighting system luminal comfort of the users is required. However, we note that the areas closest to the windows have adequate illuminance next, and according to the perceptions of the students, levels of natural light these areas are sufficient. Thus, seeking reduction in energy consumption, we suggest the readjustment of the drive system of rows of lamps near windows.

Keywords: Daylighting, visual comfort, perception, energy efficiency, classrooms.

\section{INTRODUÇÃO}

Segundo Ochoa, Araújo e Sattler (2012) a principal função da edificação é propiciar aos seus usuários proteção e conforto para o desenvolvimento de suas atividades. Toda edificação, independentemente do uso ao qual se destina, necessita de condições adequadas, que envolvam o conforto ambiental, seja ele lumínico, térmico, acústico ou ergonômico (FERVENÇA e BARTHOLOMEI, 2012).

Atingir um desempenho satisfatório envolve um correto planejamento arquitetônico, que deve levar em consideração as diferentes condições climáticas. Dessa forma, a variável ambiental iluminação, pode afetar a sensação do indivíduo, produzindo conforto ou desconforto, alterando seu desempenho na realização de uma determinada tarefa visual, além de influenciar diretamente na eficiência energética da edificação (OCHOA, ARAÚJO e SATTLER, 2012; SARDEIRO e ROTTA NETO, 2012).

Conforme Carlo (2008), no meio urbano, as edificações são responsáveis por grande parte do consumo de energia elétrica, sendo que no Brasil, em edifícios comerciais, de serviços e públicos cerca de $20 \%$ da energia total é consumida pelo sistema de iluminação. Para Didoné e Bittencourt (2007), a inadequação dos edifícios as condições climáticas locais, geram a ineficiência dos sistemas de iluminação natural. Logo, para garantir o conforto lumínico dos indivíduos, o ambiente passa a ser dependente do sistema de iluminação artificial, o que aumenta o consumo energético da edificação.

A utilização da luz natural nos ambientes apresenta vantagens, como: a adequada interpretação das cores; o contato com o meio exterior, conferindo a sensação de passagem do tempo; além da economia no consumo de energia elétrica através da redução no uso dos sistemas de iluminação artificial.

A iluminação de um ambiente é satisfatória, de acordo com Sardeiro e Rotta Neto (2012), quando este possui uma quantidade e qualidade adequada de luz, permitindo a execução das atividades sem esforços e sem ocasionar a fadiga visual. Nesse contexto, Fervença e Bartholomei (2012) asseguram que a condição de conforto não pode ser analisada levando em consideração apenas os aspectos técnicos, mas, sobretudo a sensação de bem estar do usuário.

No caso de um ambiente escolar, a qualidade do processo ensino-aprendizagem que ocorre em sala de aula é função direta do grau de conforto ambiental apresentado pelo espaço, sendo que a iluminância adequada aliada a uma distribuição uniforme da luz são elementos essenciais para ao bom desempenho e estimulo dos alunos (ARAÚJO, GONÇALVES e CABÚS, 2007; DORIGO e KRÜGER, 2007; GARROCHO, 2005).

Dessa forma, o bom desempenho do sistema de iluminação natural, além do aumento da satisfação e produtividade dos alunos e dos professores, pode gerar ganhos significativos quanto à eficiência energética da edificação. 


\section{OBJETIVO}

Este trabalho tem como objetivo principal analisar o desempenho da iluminação natural de quatro salas de aula de desenho de uma instituição de ensino superior situada em Vitória (ES), a fim de verificar as condições de conforto a que os usuários estão submetidos. Considerando a percepção dos alunos, o objetivo específico desta pesquisa é comparar os resultados técnicos obtidos através das medições de iluminância in loco com a percepção em relação à iluminação natural dos usuários dessas salas de aula, coletada através de questionários, além de propor modificações no sistema de iluminação buscando a redução do consumo energético da edificação em estudo.

\section{METODOLOGIA}

Os procedimentos metodológicos empregados no desenvolvimento do estudo estão sintetizados no fluxograma representado pela Figura 1.

\section{Figura 1 - Fluxograma dos procedimentos metodológicos empregados no estudo.}

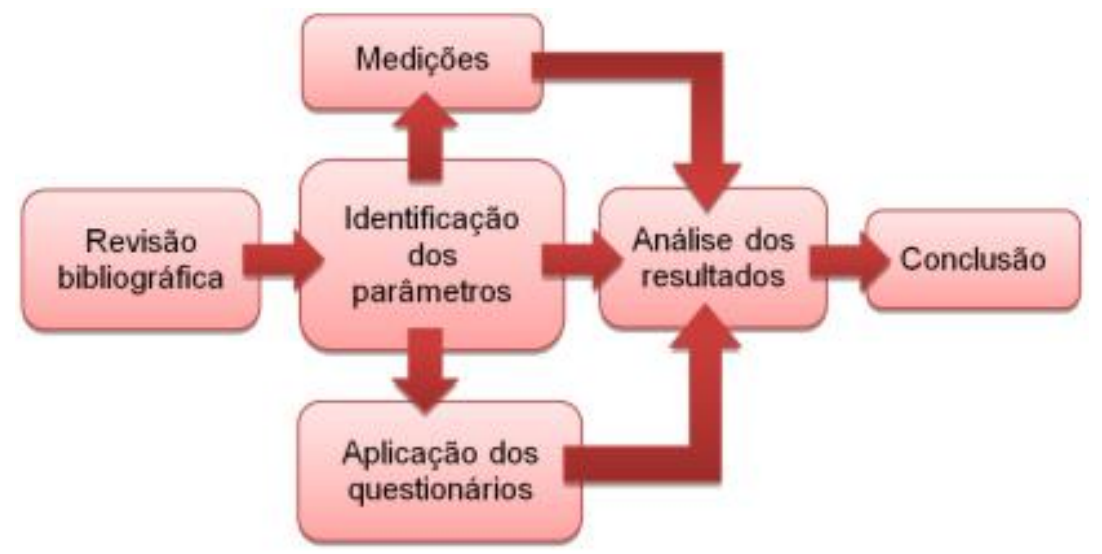

Fonte: Acervo pessoal

A metodologia do trabalho abrangeu a revisão bibliográfica sobre o uso da iluminação natural em ambientes internos, principalmente em edificações escolares. A revisão contemplou os parâmetros de avaliação do conforto visual em salas de aula, tendo como base trabalhos já realizados por outros pesquisadores e descritos em artigos de anais de congressos e periódicos, dissertações e teses publicadas no Brasil. Ainda nessa etapa foram levantados os níveis de iluminância recomendados para a obtenção de conforto visual em salas de aula de desenho, sendo adotado o nível de iluminância ideal para estes ambientes de 700 lux na área de trabalho, como indicado pela norma NBR 8995-1 (ABNT, 2013).

Foram selecionadas quatro salas de aula de desenho, com as janelas voltadas para a fachada com orientação geográfica sul. A sala A localiza-se no $1^{\circ}$ andar, sala $\mathrm{C}$ no $2^{\circ}$ andar e as salas B e D no $3^{\circ}$ e último andar do mesmo edifício. A Figura 2 mostra o entorno com as obstruções externas - um edifício localizado a 7 metros de distância e com o mesmo gabarito do edifício em estudo, e algumas árvores (pinheiros) com a altura próxima a dos edifícios e localizadas entre as duas edificações. 


\section{Figura 2 - Entorno (Obstruções externas) visto da janela da sala B.}

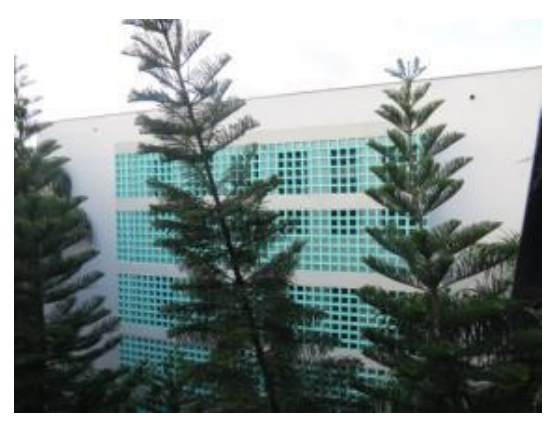

Fonte: Acervo pessoal

Com as salas selecionadas, foram coletadas as informações específicas de cada uma, como descrito no Quadro 1.

Quadro 1 - Características físicas das salas analisadas.

\begin{tabular}{|c|c|c|c|c|}
\hline \multirow{2}{*}{ Características } & \multicolumn{4}{|c|}{ Salas } \\
\cline { 2 - 5 } & A & B & C & D \\
\cline { 2 - 5 } & $9,00 \times 10,70$ & $9,00 \times 13,80$ & $9,00 \times 10,00$ & $9,00 \times 12,20$ \\
\hline Dimensões $(\mathrm{m})$ & 2,75 & 2,70 & 2,65 & 2,65 \\
\hline Pé direito $(\mathrm{m})$ & Branco & Branco & Branco & Branco \\
\hline Cor da parede & Cinza & Branco & Cinza & Branco \\
\hline Cor do teto & Cinza & Cinza & Cinza & Cinza \\
\hline Cor do piso & Branco & Branco & Branco & Branco \\
\hline Cor da área de trabalho & 0,558 & 0,627 & 0,584 & 0,586 \\
\hline Fator WWR ${ }^{2}$ & Basculante & Basculante & Basculante & Basculante \\
\hline Tipo de janela & & & & \\
\hline
\end{tabular}

Notas: ${ }^{1}$ Relação: área de abertura / área da parede externa.

Fonte: Acervo pessoal.

A partir da análise da revisão bibliográfica, também foram definidos os métodos utilizados para a avaliação do desempenho da iluminação natural e das condições de conforto a que os usuários estão submetidos. Os métodos usados foram medições de iluminância in loco, para coleta dos dados técnicos, e aplicação de um questionário aos alunos usuários das salas, para coleta das percepções quanto a iluminação natural.

As medições in loco foram realizadas em dez dias com predominância de céu claro, sendo estes os intervalos entre os dias 21 à 25/10/2013 e 09 à 13/12/2013, em três horários matutinos: 6:00, 8:30 e 11:00 horas (desconsiderando o horário de verão). Para estas medições foram utilizados quatro aparelhos do tipo luxímetro digital, modelo MLM-1332, da marca Minipa. O procedimento de medição foi realizado de acordo com as recomendações da NBR 15215-4 (ABNT, 2005). De acordo com esta norma, o número de pontos para medição deve ser calculado em função da área do ambiente e do tamanho das aberturas, no caso das salas em estudo o resultado do cálculo recomenda 25 pontos. Porém, o número de pontos de medição foi reduzido para 15 pontos para cada sala, devido a limitação do número de luximetros para medição. 
Objetivando verificar a percepção dos alunos quanto ao desempenho da iluminação natural nas salas em estudo foi aplicado um questionário, elaborado com base nas pesquisas de Correia (2008), Fervença e Bartholomei (2012), Ochoa, Araújo e Sattler (2012) e Sardeiro e Rotta Neto (2012). O questionário possuía onze perguntas fechadas - as quatro primeiras perguntas caracterizavam o aluno e a sala, as demais se referiam a percepção do aluno quanto ao sistema de iluminação natural - e uma aberta. Esta última pergunta propõe ao aluno indicar alternativas para melhorar o desempenho do sistema de iluminação da sala de aula, incitando a análise crítica sobre o tema.

O questionário foi aplicado no dia 25/10/2014 às 8:30 horas, seguindo o horário das medições in loco. Foram aplicados 153 questionários que, foram preenchidos pelos próprios alunos, com a supervisão de um pesquisador envolvido neste trabalho. Os alunos, usuários das salas em estudo, são estudantes dos cursos de Engenharia Civil e Arquitetura e urbanismo, sendo $85 \%$ na faixa etária de 17 a 21 anos.

Ao fim da pesquisa os dados obtidos nas medições de iluminância in loco foram comparados com a percepção dos usuários das quatro salas estudadas, para a verificação do desempenho da iluminação natural nestas salas.

\section{ANÁLISE DOS RESULTADOS}

Os dados coletados durante as medições de iluminância in loco e através dos questionários foram tabulados na forma de gráficos para que estes fossem analisados e comparados, gerando assim os resultados desta pesquisa.

Durante as medições notou-se que a distribuição da iluminação natural nas salas não era uniforme, consequência da localização unilateral das janelas (Figura 3).

Figura 3 - Vista interna das quatro salas estudadas.

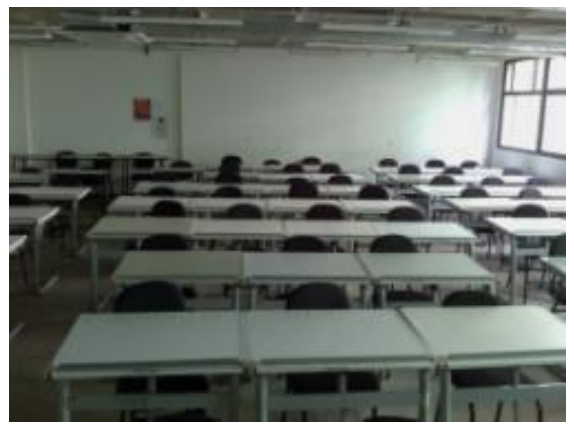

(a) Sala A

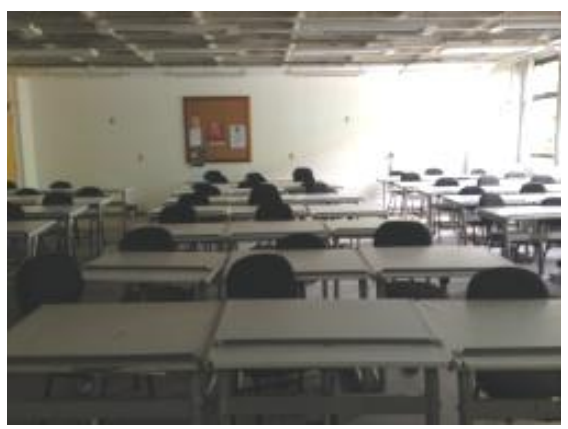

(c) Sala C

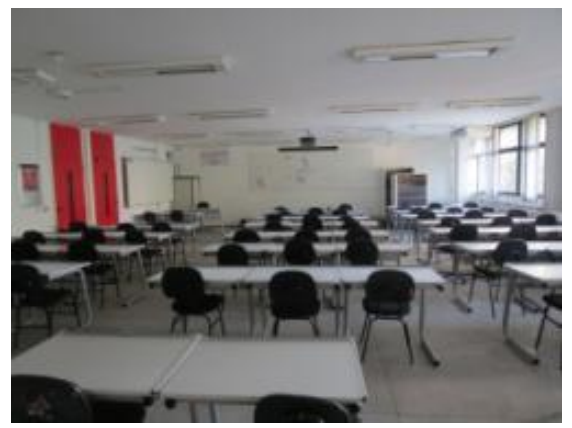

(b) Sala B

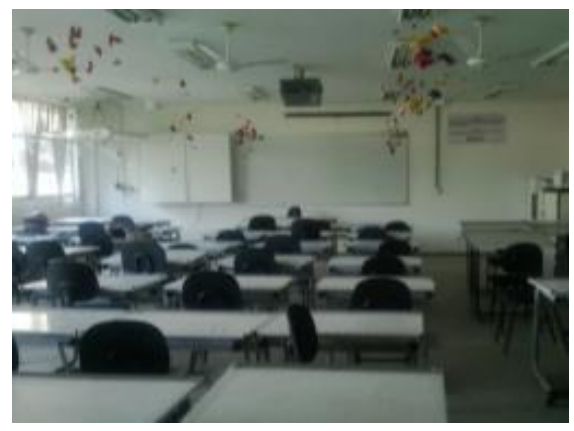

(d) Sala D

Fonte: Acervo pessoal. 
Por este motivo e para facilitar a compreensão dos resultados, os pontos de medição foram agrupados por fileiras de pranchetas, como visto na Figura 4. Dessa forma, as análises foram realizadas subdividindo as salas em 3 partes, ou seja, 3 fileiras de pranchetas.

\section{Figura 4 - Planta baixa esquemática das salas estudadas, com a locação dos} pontos de medição in loco e a divisão por fileiras de pranchetas.

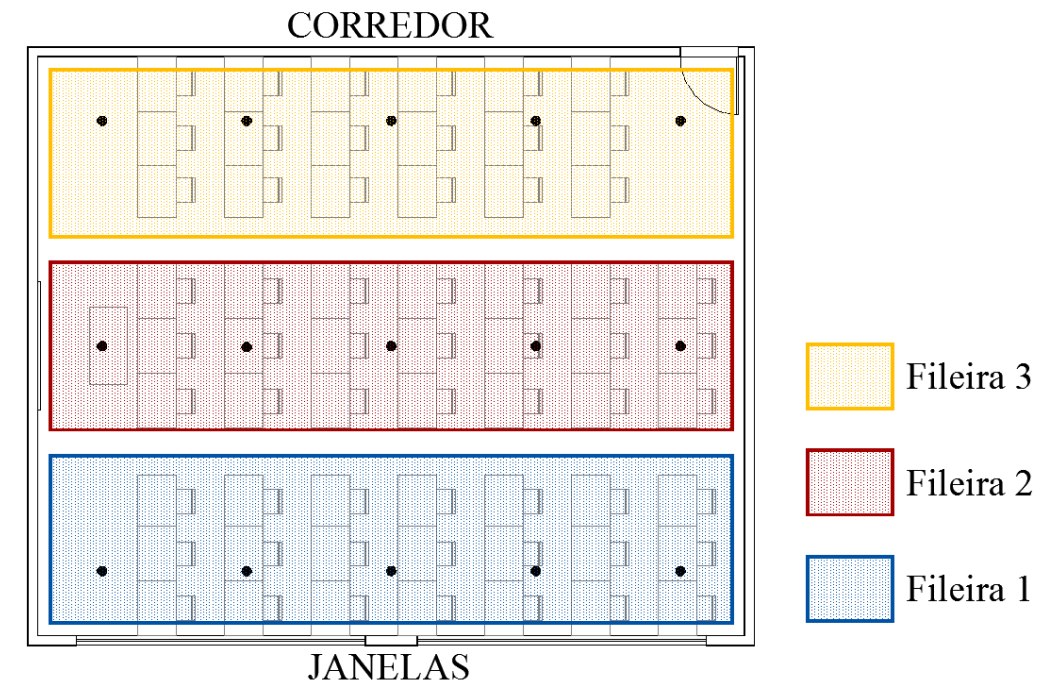

Fonte: Acervo pessoal.

Os gráficos apresentados nas Figuras 5 a 7 representam os resultados médios das medições de iluminância in loco por horários de medição.

\section{Figura 5 - Iluminância média encontrada nas medições realizadas às 6:00 horas}

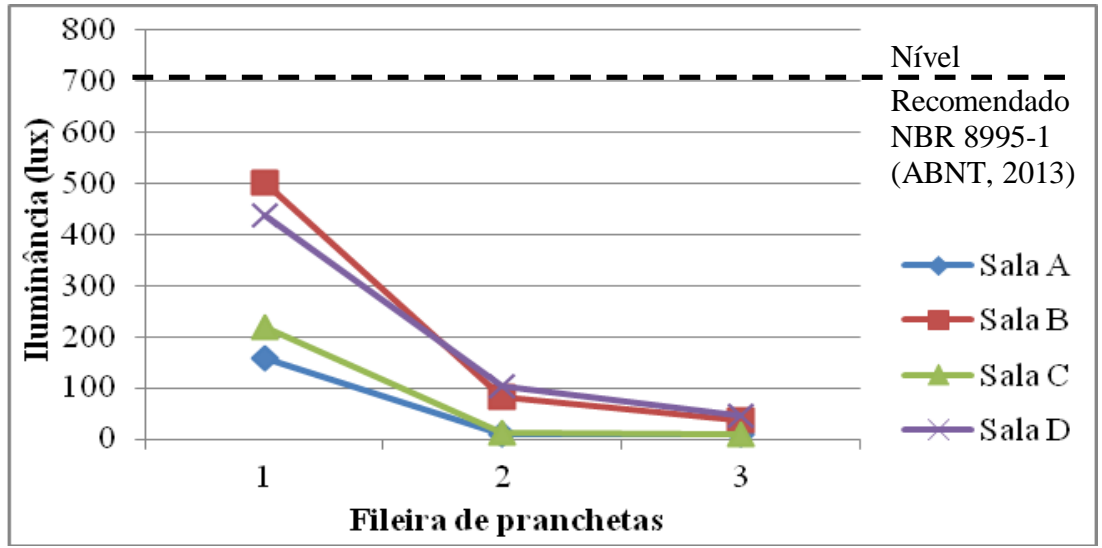

Fonte: Acervo pessoal. 
Figura 6 - Iluminância média encontrada nas medições realizadas às 8:30 horas

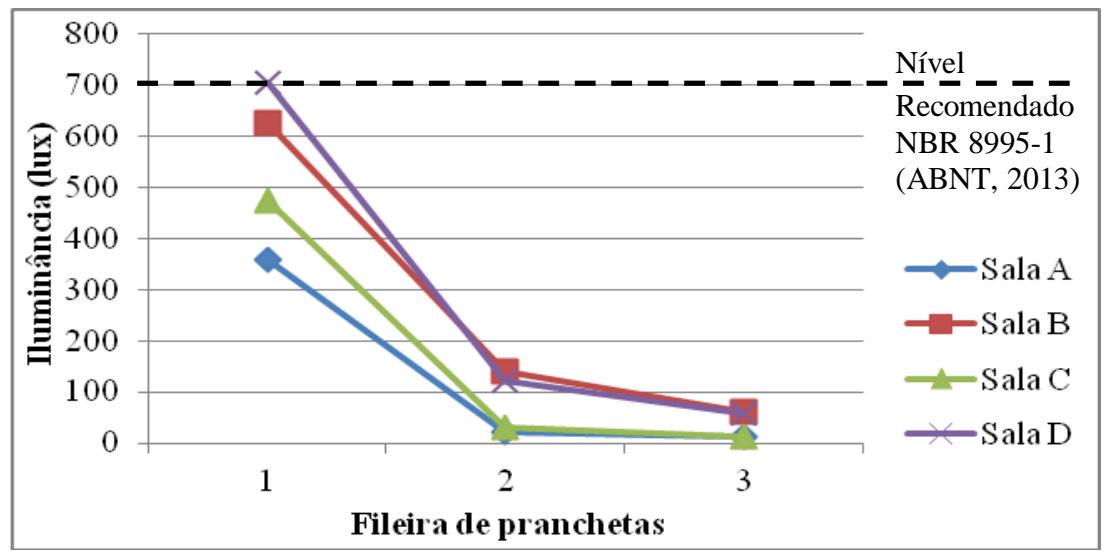

Fonte: Acervo pessoal.

Figura 7 - Iluminância média encontrada nas medições realizadas às 11:00 horas

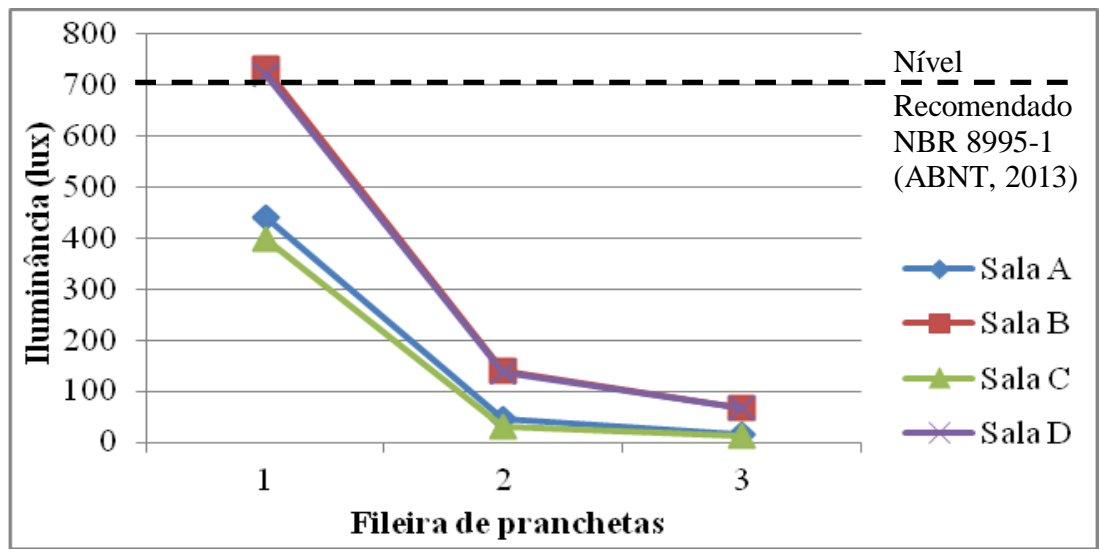

Fonte: Acervo pessoal.

A partir da análise dos resultados observou-se que às 6:00 horas nenhum ponto de nenhuma das salas estudadas atingiu os níveis de iluminância adequados. Porém, nos horários de 8:30hs e 11:00hs, na área onde estão as pranchetas da fileira 1 das salas B e $\mathrm{D}$, a iluminação natural atingiu níveis de iluminância próximos aos níveis recomendados pela NBR 8995-1 (ABNT, 2013).

Desse modo pode-se afirmar que as obstruções externas efetivamente influenciaram nos resultados, tendo em vista que as salas $\mathrm{B}$ e $\mathrm{D}$ estão localizadas no último andar do edifício, e as obstruções externas seguem o mesmo gabarito deste. A sala A, que apresentou os menores níveis de iluminância na área próxima as janelas, está no $1^{\circ}$ andar, sofrendo assim maior influencia das obstruções externas.

Ao analisar os resultados das fileiras 2 e 3, conclui-se que, devido aos baixos níveis de iluminância encontrados durante as medições in loco, estas áreas dependem do sistema de iluminação artificial para atingir a iluminância de 700 lux, adequada a realização da tarefa a qual estas salas se destinam.

As figuras 8, 9, 10 e 11 apresentam os gráficos com os resultados da tabulação de algumas questões do questionário que foi utilizado para coletar as percepções dos alunos. 
Figura 8 - Como você classifica a iluminação natural nesta sala?
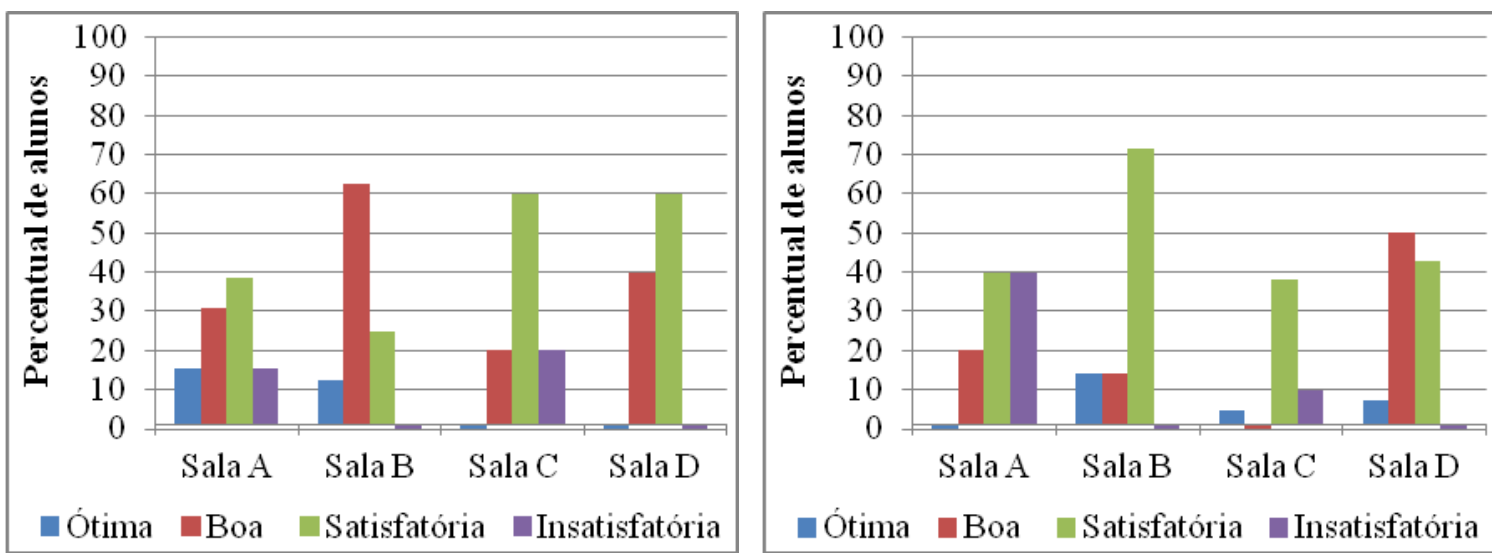

(a) Fileira 1

(b) Fileira 2

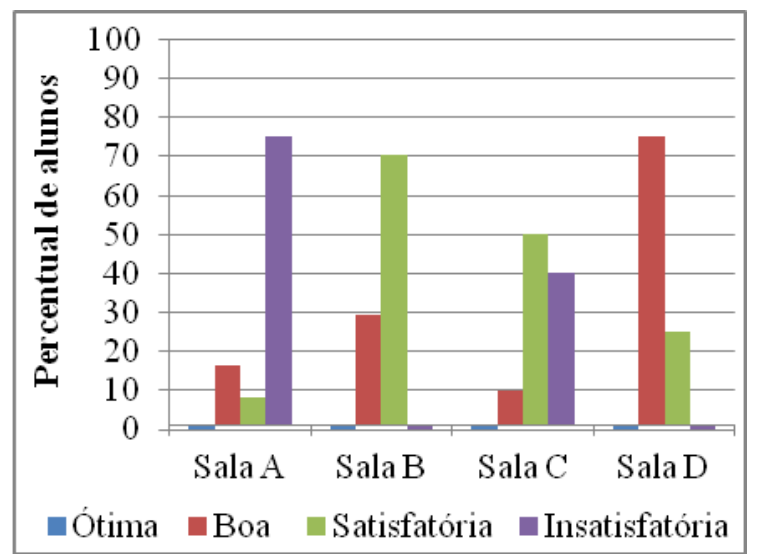

(b) Fileira 3

Fonte: Acervo pessoal.

Figura 9 - Como você classifica a quantidade e distribuição das janelas?

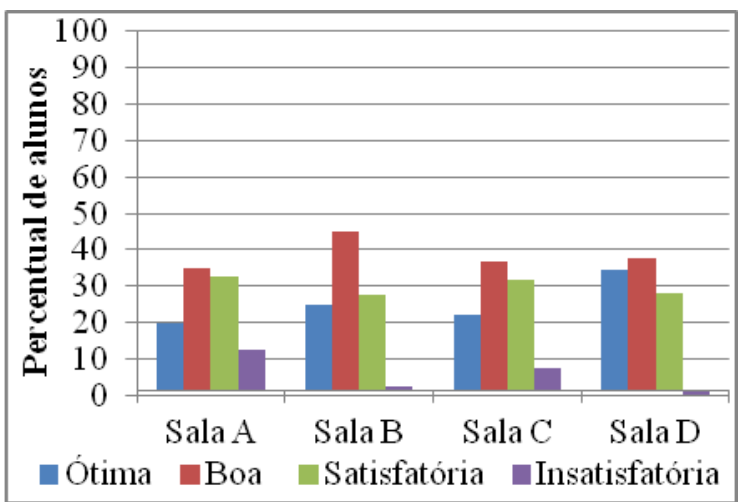

Fonte: Acervo pessoal.
Figura 10 - Você consegue desenvolver com facilidade todas as atividades com a iluminação artificial desligada?

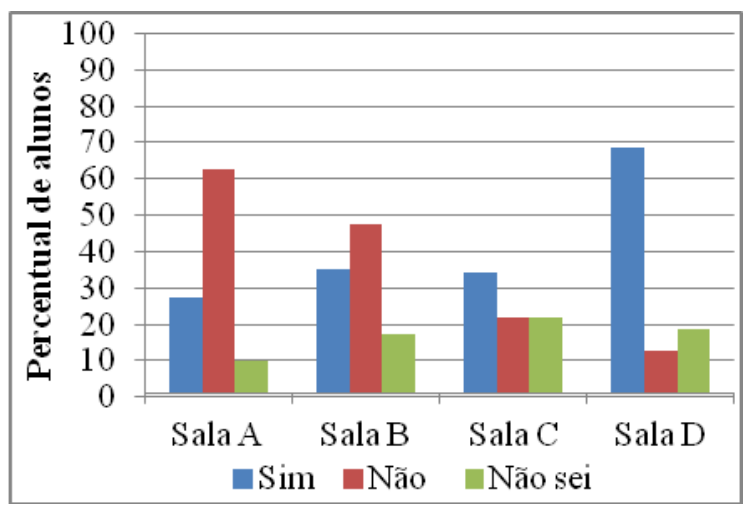

Fonte: Acervo pessoal. 
Figura 11 - Com que frequência você considera necessário utilizar a iluminação artificial nesta sala?

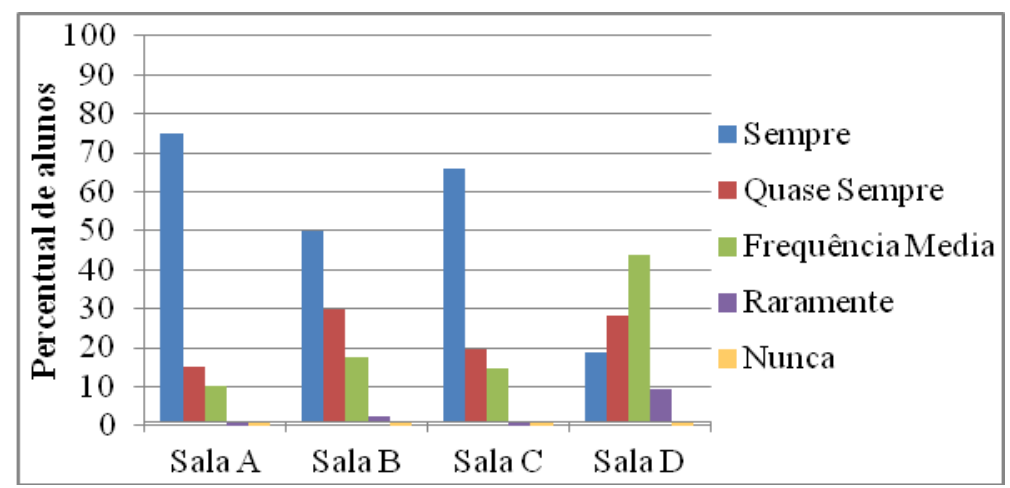

Fonte: Acervo pessoal.

Os resultados dos questionários aplicados aos alunos que utilizam as salas estudadas comprovam os resultados obtidos com as medições in loco, ou seja, a fileira próxima à janela possui melhores níveis de iluminação natural, promovendo bons índices de conforto lumínico aos usuários. No entanto, mesmo encontrando-se índices muito baixos de iluminância nas medições in loco para as fileiras 2 e 3, alguns alunos ainda consideram este nível satisfatório e classificam como boa a quantidade e a distribuição das janelas nas salas.

Quanto à dependência da iluminação artificial para manter o conforto visual adequado a realização de tarefas, a maioria dos alunos, com exceção da sala $\mathrm{D}$, afirmou que não conseguem desenvolver as atividades com a iluminação artificial desligada, admitindo o baixo desempenho do sistema de iluminação natural.

As demais questões se referiam a influência das cores das superfícies internas e do entorno no desempenho da iluminação natural nas salas estudadas. Os resultados indicam que os alunos perceberam que as cores claras auxiliaram no desempenho deste sistema. Quanto ao entorno, os alunos das salas A e C classificaram como média influência, já os das salas B e D pequena influência, confirmando os dados técnicos.

Assim, como a condição de conforto não pode ser analisada levando em consideração apenas os aspectos técnicos, mas também a sensação de bem estar do usuário, esta pesquisa confrontou ambos os dados, técnicos e percepções dos usuários. Dessa forma, pode-se afirmar que o sistema de iluminação natural não é suficiente para promover os níveis de iluminância adequados, bem com a sensação de conforto visual do usuário, para este fim é necessária a utilização constante do sistema de iluminação artificial.

\section{CONSIDERAÇÕES FINAIS}

Com base nos resultados observados é possível concluir que:

- Os níveis de iluminância mostraram-se insuficientes em todas as salas analisadas para o primeiro horário de medição, 6:00 horas. Já nos horários de 8:30hs e 11:00hs, nas áreas mais próximas as janelas das salas localizadas no último andar, a iluminação natural atingiu níveis de iluminância adequados.

- As obstruções externas influenciaram diretamente no desempenho da iluminação natural, tendo em vista que nota-se os melhores resultados para as salas localizadas no último andar do edifício, onde o entorno tem menor influência. 
- Nota-se que, as salas analisadas dependem do sistema de iluminação artificial para atingir a iluminância adequada, já que os níveis encontrados durante as medições in loco foram insuficientes para a maior parte da área das salas.

- As percepções dos usuários comprovam os resultados obtidos com as medições in loco, mostrando que, realmente, as áreas mais próximas as janelas promovem melhores índices de conforto lumínico. Além disso, apesar de considerarem boa a quantidade e a distribuição das janelas, a maior parte destes usuários alega que não conseguem desenvolver as atividades com a iluminação artificial desligada.

Assim, observou-se que o sistema de iluminação natural não é suficiente para promover os níveis de iluminância adequados, bem com a sensação de conforto visual do usuário, para este fim é necessária a utilização constante do sistema de iluminação artificial. Dessa forma, para manter os níveis adequados de conforto lumínico e promover a redução no consumo de energia elétrica, sugere-se a readequação do sistema de acionamento das luminárias, distribuindo os circuitos independentes e paralelos à parede que contém as janelas.

\section{REFERÊNCIAS}

ARAÚJO, M. R.; GONÇALVES, V.; CABÚS, R. Análise da iluminação natural a partir de elementos vazados. In: ENCONTRO NACIONAL DE CONFORTO NO AMBIENTE CONSTRUÍDO, 9, 2007, Ouro Preto. Anais... Ouro Preto: ANTAC, 2007.

ASSOCIAÇÃO BRASILEIRA DE NORMAS TÉCNICAS (ABNT). NBR 8995-1: Iluminação de ambientes de trabalho - Interior. Rio de Janeiro, 2013.

NBR 15215-4: Iluminação natural - Verificação experimental das condições de iluminação interna de edificações - Método de medição. Rio de Janeiro, 2011.

CARLO, J. Desenvolvimento de metodologia de avaliação da eficiência energética do envoltório de edificações não-residenciais. 2008. 215f. Tese (Doutorado em Engenharia Civil) - Universidade Federal de Santa Catarina, Florianópolis.

CORREIA, A. G. U. Avaliação Pós-Ocupação da iluminação natural das salas dos setores de aulas teóricas da Universidade Federal do Rio Grande do Norte. 2008. 175f. Dissertação (Mestrado em Arquitetura e Urbanismo) - Universidade Federal do Rio Grande do Norte, Natal.

DINDONÉ, E. L.; BITTENCOURT, L. S. Iluminação natural produzida pelo uso de sheds em ambientes escolares. In: ENCONTRO NACIONAL DE CONFORTO NO AMBIENTE CONSTRUÍDO, 9, 2007, Ouro Preto. Anais... Ouro Preto: ANTAC, 2007.

DORIGO, A. L.; KRÜGER, E. L. Uso de dispositivos de sombreamento em salas de aula Avaliação de método proposto por Olgyay. In: ENCONTRO NACIONAL DE CONFORTO NO AMBIENTE CONSTRUÍDO, 9, 2007, Ouro Preto. Anais... Ouro Preto: ANTAC, 2007.

FERVENÇA, Y. S. G.; BARTHOLOMEI, C. L. B. Escolas Públicas: Avaliação do conforto lumínico em Presidente Prudente - SP. In: ENCONTRO NACIONAL DE TECNOLOGIA DO AMBIENTE CONSTRUÍDO, 14, 2012, Juiz de Fora. Anais... Juiz de Fora: ANTAC, 2012.

GARROCHO, J. S. Luz natural e projeto de arquitetura: Estratégias para iluminação zenital em centros de compras. 2005. 129f. Dissertação (Mestrado em Arquitetura e Urbanismo) Universidade de Brasília, Brasília.

OCHOA, J. H.; ARAÚJO, D. L.; SATTLER, M. A. Análise do conforto ambiental em salas de aula: Comparação entre dados técnicos e a percepção do usuário. Ambiente Construído, v. 12, n. 1, p. 91-114, jan./mar. 2012.

SARDEIRO, P.; ROTTA NETO, A. Avaliação do desempenho luminoso em salas de aula: Estudo de caso. In: ENCONTRO NACIONAL DE TECNOLOGIA DO AMBIENTE CONSTRUÍDO, 14, 2012, Juiz de Fora. Anais... Juiz de Fora: ANTAC, 2012. 